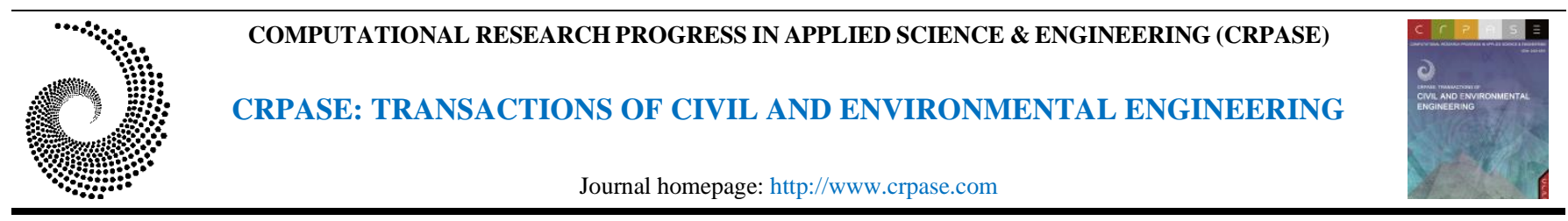

CRPASE: Transactions of Civil and Environmental Engineering 8 Article ID: 2227, 1-7, Special Issue: NCTT 2021

ISSN 2423-4591

Research Article

\title{
Understanding the Factors Affecting Urban Vehicle-to-Vehicle Crash Severity with Focus on Drivers' Route Familiarity
}

\author{
Mahyar Vahedi Saheli* \\ Department of Civil Engineering, Faculty of Engineering, University of Guilan, Rasht, Iran
}

\begin{tabular}{ll}
\hline Keywords & Abstract \\
\cline { 1 - 3 } $\begin{array}{l}\text { Urban crash severity, } \\
\text { Vehicle-to-vehicle }\end{array}$ & $\begin{array}{l}\text { Human factors are usually of paramount importance when it comes to traffic crashes. } \\
\text { Drivers' route familiarity or unfamiliarity is a critical human-related factor that has less been } \\
\text { considered in the literature. This factor can lead to inattention, distraction, and dangerous } \\
\text { Unfamiliar drivers, }\end{array}$ \\
$\begin{array}{l}\text { Familiar drivers, } \\
\text { bohaviors due to familiar drivers' over-confidence or unfamiliar drivers' insufficient } \\
\text { knowledge of road geometry and environment. The main objective of this study is to } \\
\text { discover the factors affecting the severity of vehicle-to-vehicle crashes in Rasht city (in } \\
\text { northern Iran) involving unfamiliar and familiar drivers using a logistic regression model. } \\
\text { The results indicate the significant effect of human factors such as driver's familiarity and } \\
\text { age, collision type, angle and reason, temporal factors (season and time of day), vehicles } \\
\text { involved in the crash, and environmental conditions on the injury severity of vehicle-to- } \\
\text { vehicle crashes in urban roads. The results of this study can be used by policymakers and } \\
\text { implementers to take appropriate measures to reduce the severity of vehicle-to-vehicle } \\
\text { crashes in urban areas. }\end{array}$ \\
\hline
\end{tabular}

\section{Introduction}

Traffic crashes are a leading cause of injury and death in many countries worldwide. Iran is one of the developing countries with high rates of traffic-related injuries and deaths. The proportion of traffic injuries in Iran is higher than in most other parts of the middle-east and the rest of the world. Road traffic crashes are also one of the country's most serious problems and among the top five leading causes of death in Iran [1].

The five categories of contributing factors to traffic collisions are human, vehicle, road, environment, and traffic $[2,3]$. Research has shown that human factors play a significant role in about $90 \%$ of crashes [4]. Among all human-related crash variables, one of the most frequent driver-related critical errors is driver distraction [4-7]. The issue of driver distraction can be closely linked to the drivers' route familiarity, which however is less considered in the literature.

A route familiar driver travels on a route well-known from long or close association, and traveling on that specific route made up of various road features has been the stimulus frequently encountered [8]. Both familiarity and unfamiliarity with roads may have adverse effects on driving tasks. High route familiarity can cause driving distraction and overconfident driving behaviors like overspeed driving to reduce the travel time [9]. On the other hand, high route unfamiliarity may lead to driving errors due to unfamiliar road features [10]. At first glance, unfamiliar drivers may seem safer than familiars since their attentional capacity is strongly focused on collecting information related to the road environment. Therefore, because the road is not well-known, they should be less likely to be distracted and less prone to speeding and risk-taking behaviors [9]. Yet, this good

* Corresponding Author: Mahyar Vahedi Saheli

E-mail address: mahyarvahedi@msc.guilan.ac.ir

Received: 16 November 2021; Revised: 18 December 2021; Accepted: 17 January 2022

https://doi.org/10.52547/crpase.8.2227

Academic Editor: Mahdi Feizbahr

Please cite this article as: M. Vahedi Saheli, Understanding the Factors Affecting Urban Vehicle-to-Vehicle Crash Severity with Focus on Drivers' Route Familiarity, Computational Research Progress in Applied Science \& Engineering, CRPASE: Transactions of Civil and Environmental Engineering 8 (2022) 1-7, Article ID: 2227. 
practice concept is often followed in road design guidelines: road design should be considered for users who are driving on a roadway for the first time and are unfamiliar with its characteristics [11].

It is unexpected and, of course, unsafe for all drivers to encounter a sudden sharp curve after a long stretch of straight road because the reality (the unexpected curve) differs from the expectations formed during the previous long section of the straight road [9]. However, the curve is not, in fact, unexpected for all drivers. It is just unexpected for drivers who never/rarely traveled on that road (unfamiliar drivers), and it could lead to errors in speed and steering [9]. The justification mentioned above might easily explain the reason unfamiliar drivers are likely to exhibit road safety weaknesses.

Furthermore, driver route familiarity indicates the driver's awareness of the overall driving environment, road traffic congestion, the best rescue route after a crash, and the direction of invisible objectives that are all closely linked to the severity of the crash injury $[10,12,13]$.

This research aims to identify contributory factors (including the familiarity and unfamiliarity of at-fault and not-at-fault drivers) that significantly influence the injury severity of vehicle-to-vehicle crashes in Rasht, the biggest city and the capital of Guilan Province of Iran, by employing a logistic regression model. Guilan Province is located in northern Iran, host to many tourists (unfamiliar drivers) who annually travel to the north of Iran on holidays [14-16].

The paper starts with an overview of the literature on the impact of familiar and unfamiliar drivers on severity, frequency, and risk of crashes. The data and methodology are then described, followed by a discussion of the model estimation. At last, a summary of findings is presented.

\section{Literature Review}

Previous studies on the effect of familiar and unfamiliar drivers on road crashes have reported both positive and negative outcomes [10].

Ref. [17] discovered that 49 percent of international drivers and motorcyclists involved in road crashes in Australia that resulted in at least one fatality (single and multi-vehicle) died, and 20 percent were hospitalized, while the percentages for all drivers were 44 percent and 11 percent, respectively. They also speculated that the disparity could be due to the unfamiliar driver's higher involvement in single-vehicle collisions or differences in safety belt use compared to Australians.

Ref. [18] found that drivers involved in collisions with trucks are less likely to experience severe injuries on a roadway they are unfamiliar with. According to Ref. [19], drivers traveling on familiar roadways are more likely to be involved in run-off-road collisions (64\% of single-vehicle crashes involving familiar drivers were run-off-road, compared to the $54 \%$ of the unfamiliar ones).

Ref. [20] examined out-of-state drivers in three different states of the US and found that their probabilities of being involved in an at-fault single-vehicle collision were much greater than those of in-state drivers. Ref. [21] investigated the effect of distance between the crash location and the driver's residence on crash fault determination, predicting that drivers traveling more than 50 miles from their residence have a roughly $50 \%-200 \%$ increased likelihood of being atfault compared to familiar drivers.

Ref. [22] resulted that foreign drivers of heavy trucks in Norway were more likely to cause fatal crashes, which was explained as a consequence of the drivers' unfamiliarity with the roads, as well as their lack of experience with Norway's narrow roads with snow, ice, and high gradients. Ref. [23] revealed that unfamiliar drivers from diverse cultural backgrounds had considerably different injury-severity predictions than their Saudi counterparts. Non-Saudi drivers, for example, are more prone to be involved in fatal singlevehicle crashes in Riyadh, Saudi Arabia. Additionally, it was shown that unfamiliar drivers from countries that drive on the opposite side of the road had a greater possibility of both no injuries and fatalities.

The research above demonstrates conclusively that unfamiliar drivers may have various crash risks and resulting injury severities compared to familiars. The purpose of this study is to examine this issue with Iranian urban crash data, focusing on resulting injury severities of vehicle-to-vehicle crashes involving familiar and unfamiliar drivers.

\section{Data and Method}

\subsection{Study Area, Database, and Variables Definition}

Guilan is the $28^{\text {th }}$ biggest province in Iran, while it is the $12^{\text {th }}$ province by population $[16,24,25]$. Rasht (Figure 1 ) is its capital and one of the most congested cities in Iran, and the most populous city in the north of Iran, with high traffic volume most days during the year [26]. According to the 2016 official census, the city's population is 680,000 . The urban population of Rasht has increased almost 1.5 times during the past three decades and experienced an average annual growth of 3.3 percent [27]. The result of such rapid population growth is the uncontrolled growth and traffic congestion in the city. On average, 250,000 vehicles cross the city every day [28].

The crash data is consisted of six-year records of crashes occurring from March 21, 2015, through March 20, 2021, and was obtained from the traffic center of the Guilan urban police department. The database contains 15000 crash records, including 7500 vehicle-to-vehicle crashes. After eliminating the unknown records, 6189 records of vehicleto-vehicle crashes remained for modeling purposes (motorcycle-involved, multi-vehicle crashes, and work zone-related crashes [29] are removed from the database as they are inherently different from vehicle-to-vehicle crashes). The crash data include various factors, including time and location of the crash, driver attributes (such as age and gender), vehicle characteristics (such as company, model, type, and number), road-related and environmental factors (such as weather and lighting condition) and crash attributes (such as reason, type, angle, and severity of crash). 


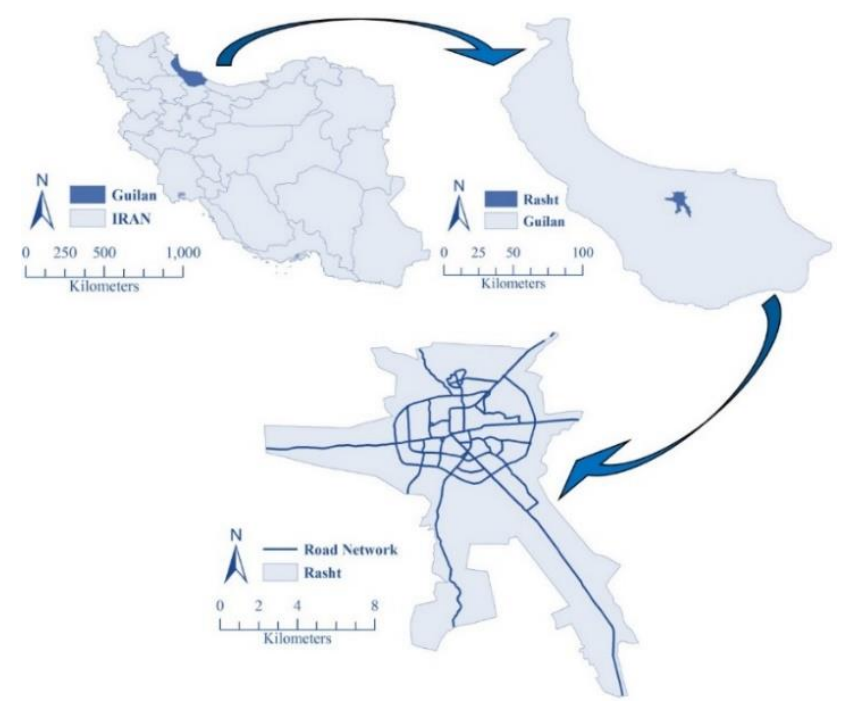

In this paper, a driver was presumed familiar if their vehicle number was for Guilan province; otherwise, they were supposed to be unfamiliar (travelers from other provinces of Iran). The percentages of familiar and unfamiliar drivers in data were $78.86 \%$ and $21.14 \%$, respectively.

As it remained only 15 fatal crashes after eliminating unknown records, fatal and injury crashes were integrated. Therefore, the dependent variable is a binary variable with the value of 1 if the crash severity is fatal or injury; and 0 if the crash severity is no injury [3]. The dataset includes 1403 injury/fatal and 4786 no injury vehicle-to-vehicle crashes.

Table 1 represents a summary of the variables used for modeling in this study. This summary includes a description of each variable as well as its maximum, minimum, mean, and standard deviation values.

Figure 1. Study area

Table 1. Data summary and descriptive statistics of explanatory variables

\begin{tabular}{|c|c|c|c|c|c|}
\hline Variable & Mean & S.D. & Min. & Max. & Description \\
\hline \multicolumn{6}{|c|}{ Temporal factors } \\
\hline ERMRN & 0.083 & 0.275 & 0 & 1 & 1 if the crash is occurred on early morning; 0 if otherwise \\
\hline MORN & 0.197 & 0.397 & 0 & 1 & 1 if the crash is occurred on morning; 0 if otherwise \\
\hline AFTRN & 0.408 & 0.492 & 0 & 1 & 1 if the crash is occurred on afternoon; 0 if otherwise \\
\hline NIGHT & 0.312 & 0.463 & 0 & 1 & 1 if the crash is occurred on night; 0 if otherwise \\
\hline WKND & 0.274 & 0.446 & 0 & 1 & 1 if the crash is occurred on weekend; 0 if otherwise \\
\hline SPRNG & 0.228 & 0.420 & 0 & 1 & 1 if the crash is occurred on spring; 0 if otherwise \\
\hline SUM & 0.257 & 0.437 & 0 & 1 & 1 if the crash is occurred on summer; 0 if otherwise \\
\hline WINTR & 0.280 & 0.449 & 0 & 1 & 1 if the crash is occurred on winter; 0 if otherwise \\
\hline \multicolumn{6}{|c|}{ Human factors } \\
\hline AFUNF & 0.213 & 0.410 & 0 & 1 & 1 if the at-fault driver is unfamiliar; 0 if otherwise \\
\hline AFYNG & 0.322 & 0.467 & 0 & 1 & 1 if the at-fault driver is younger than 31 years old; 0 if otherwise \\
\hline AFOLD & 0.101 & 0.302 & 0 & 1 & 1 if the at-fault driver is older than 55 years old; 0 if otherwise \\
\hline AFFMAL & 0.129 & 0.336 & 0 & 1 & 1 if the at-fault driver is female; 0 if otherwise \\
\hline NAFUNF & 0.210 & 0.407 & 0 & 1 & 1 if the not-at-fault driver is unfamiliar; 0 if otherwise \\
\hline NAFYNG & 0.286 & 0.452 & 0 & 1 & 1 if the not-at-fault driver is younger than 31 years old; 0 if otherwise \\
\hline NAFFMAL & 0.140 & 0.347 & 0 & 1 & 1 if the not-at-fault driver is female; 0 if otherwise \\
\hline \multicolumn{6}{|c|}{ Vehicle-related factors } \\
\hline AFAUTO & 0.661 & 0.473 & 0 & 1 & $\begin{array}{l}1 \text { if the at-fault vehicle is an Iranian company made passenger car; } 0 \text { if } \\
\text { otherwise }\end{array}$ \\
\hline AFFOAUTO & 0.205 & 0.405 & 0 & 1 & 1 if the at-fault vehicle is a foreign company made passenger car; 0 if otherwise \\
\hline AFPKP & 0.056 & 0.231 & 0 & 1 & 1 if the at-fault vehicle is a pickup; 0 if otherwise \\
\hline AFHVY & 0.073 & 0.260 & 0 & 1 & 1 if the at-fault vehicle is a heavy vehicle; 0 if otherwise \\
\hline NAFAUTO & 0.662 & 0.473 & 0 & 1 & $\begin{array}{l}1 \text { if the not-at-fault vehicle is an Iranian company made passenger car; } 0 \text { if } \\
\text { otherwise }\end{array}$ \\
\hline NAFFOAUTO & 0.252 & 0.434 & 0 & 1 & $\begin{array}{l}1 \text { if the not-at-fault vehicle is a foreign company made passenger car; } 0 \text { if } \\
\text { otherwise }\end{array}$ \\
\hline NAFPKP & 0.047 & 0.212 & 0 & 1 & 1 if the not-at-fault vehicle is a pickup; 0 if otherwise \\
\hline NAFHVY & 0.038 & 0.191 & 0 & 1 & 1 if the not-at-fault vehicle is a heavy vehicle; 0 if otherwise \\
\hline \multicolumn{6}{|c|}{ Road and environmental factors } \\
\hline WET & 0.132 & 0.339 & 0 & 1 & 1 if the surface is wet while the crash occurred; 0 if otherwise \\
\hline ADVRSWTHR & 0.112 & 0.316 & 0 & 1 & $\begin{array}{l}1 \text { if the weather is rainy, snowy, or foggy while the crash occurred; } 0 \text { if } \\
\text { otherwise }\end{array}$ \\
\hline \multicolumn{6}{|c|}{ Crash-related factors } \\
\hline HDON & 0.103 & 0.304 & 0 & 1 & 1 if the crash was head-on; 0 if otherwise \\
\hline RREND & 0.394 & 0.489 & 0 & 1 & 1 if the crash was rear-end; 0 if otherwise \\
\hline SDIMP & 0.375 & 0.484 & 0 & 1 & 1 if the crash was side-impact; 0 if otherwise \\
\hline SDSWP & 0.128 & 0.335 & 0 & 1 & 1 if the crash was side-swipe; 0 if otherwise \\
\hline SDNCHNG & 0.095 & 0.294 & 0 & 1 & $\begin{array}{l}1 \text { if the crash occurred as a result of a sudden change in a vehicle's direction; } 0 \text { if } \\
\text { otherwise }\end{array}$ \\
\hline IGNROW & 0.245 & 0.430 & 0 & 1 & 1 if the crash occurred as a result of ignoring the ride of way; 0 if otherwise \\
\hline WRNGWAY & 0.007 & 0.083 & 0 & 1 & 1 if the crash occurred as a result of wrong-way driving; 0 if otherwise \\
\hline RVRS & 0.0364 & 0.187 & 0 & 1 & 1 if the crash occurred as a result of reversing; 0 if otherwise \\
\hline REDLIT & 0.028 & 0.165 & 0 & 1 & 1 if the crash occurred as a result of red-light running; 0 if otherwise \\
\hline DOROPN & 0.011 & 0.103 & 0 & 1 & $\begin{array}{l}1 \text { if the crash occurred as a result of sudden opening the vehicle's door; } 0 \text { if } \\
\text { otherwise }\end{array}$ \\
\hline
\end{tabular}




\subsection{Modeling and Validation}

Of all the regression models, logistic regression is often the most appropriate method when the intent is to model binary outcomes as a function of predictor variables [30]. In the logistic regression model, a latent variable is formulated by the following expression [31]:

$$
\begin{gathered}
g(x)=\beta_{0}+\beta_{1} x_{1}+\beta_{2} x_{2}+\cdots+\beta_{j} x_{j}+\cdots \\
\cdot+\beta_{p} x_{p}
\end{gathered}
$$

where $x_{j}$ is the value of the jth independent variable, with $j$ as the corresponding coefficient, for $j=1,2,3, \ldots, p$, and $p$ is the number of independent variables. With this latent variable, the conditional probability of a positive outcome is determined by:

$$
\pi(x)=\frac{\exp (g(x))}{1+\exp (g(x))}
$$

The maximum likelihood method is then employed to measure the associations by constructing the likelihood function as follows:

$$
l(\beta)=\prod_{i=1}^{n} \pi\left(x_{i}\right)^{y_{i}}\left(1-\pi\left(x_{i}\right)\right)^{1-y_{i}}
$$

where $y_{i}$ denotes the $i^{\text {th }}$ observed outcome, with the value of either 0 or 1 only, and $i=1,2,3, \ldots, n$ where $n$ is the number of observations. By maximizing the log-likelihood expression as,

$$
\begin{aligned}
L L(\beta)=\ln (l(\beta)) & \\
& =\sum_{i=1}^{n}\left\{y_{i} \ln \left(\pi\left(x_{i}\right)\right)\right. \\
& \left.+\left(1-y_{i}\right) \ln \left(1-\pi\left(x_{i}\right)\right)\right\}
\end{aligned}
$$

the best estimate of $\beta$ could be obtained accordingly [15].

To evaluate how accurately the developed model predicts crash severity, testing the model by predicting out-of-sample data is needed. This study aims to utilize a 10 -fold cross- validation process for validation. The original input data are randomly partitioned into 10 equally sized subsamples. In each iteration, one subsample is retained as the validation data for testing the models; the remaining subsamples are used as training data. After that, all subsamples are used exactly once as the validation data. The mean absolute deviation (MAD) function is used for the evaluation of the model's prediction performance as follows:

$$
M A D=\frac{1}{n} \sum_{t=1}^{n}\left|y_{\text {predicted }}-y_{\text {observed }}\right|
$$

Where $y_{\text {predicted }}$ and $y_{\text {observed }}$ are the predicted and observed values of crash severity for each record, respectively, and $n$ is the number of crash records.

\section{Results and Discussion}

After step-wising the preliminary model (a model developed using all the potential explanatory variables), the final model is designed using collinearity and goodness-offit measures. In this study, STATA 17 software was used for modeling purposes.

Table 2 shows the results for the developed logistic regression model. Parameter estimates and their standard errors, significance level ( $p$-value), and z-scores are presented for each explanatory variable in Table 2. Most candidate variables are excluded from the final model during the multicollinearity test or backward elimination [14] process, but the remains are primarily significant. The process led to a better model (in terms of variables' significance and lower standard errors).

\begin{tabular}{|c|c|c|c|c|}
\hline Parameters & Coef. & S.E. & p-value & Z-score \\
\hline ERMRN & 0.764 & 0.114 & $0.000^{* * * *}$ & 6.72 \\
\hline MORN & -0.150 & 0.095 & 0.114 & -1.58 \\
\hline AFTRN & -0.229 & 0.079 & $0.004^{* * *}$ & -2.90 \\
\hline SPRNG & 0.417 & 0.093 & $0.000^{* * *}$ & 4.51 \\
\hline SUM & 0.316 & 0.091 & $0.001^{* * *}$ & 3.46 \\
\hline AUTMN & 0.240 & 0.093 & $0.010^{* * *}$ & 2.58 \\
\hline HDON & 0.266 & 0.106 & $0.012^{* *}$ & 2.52 \\
\hline RREND & 0.143 & 0.072 & $0.046^{* *}$ & 1.99 \\
\hline AFAUTO & 0.652 & 0.114 & $0.000^{* * *}$ & 5.72 \\
\hline AFFOAUTO & -0.229 & 0.138 & $0.096^{*}$ & -1.66 \\
\hline NAFAUTO & 0.261 & 0.121 & $0.031^{* *}$ & 2.16 \\
\hline NAFFOAUTO & -1.139 & 0.149 & $0.000^{* * *}$ & -7.66 \\
\hline DRKNIT & 0.713 & 0.232 & $0.002^{* * *}$ & 3.07 \\
\hline ADVRSWTHR & 0.153 & 0.102 & 0.134 & 1.50 \\
\hline AFUNF & -0.687 & 0.092 & $0.000^{* * *}$ & -7.44 \\
\hline AFYNG & 0.120 & 0.069 & $0.084^{*}$ & 1.73 \\
\hline NAFUNF & -0.772 & 0.098 & $0.000^{* * *}$ & -7.87 \\
\hline SDNCHNG & -0.844 & 0.151 & $0.000^{* * *}$ & -5.60 \\
\hline RVRS & -0.561 & 0.219 & $0.011^{* *}$ & -2.56 \\
\hline DOROPN & -1.076 & 0.483 & $0.026^{* *}$ & -2.23 \\
\hline Constant & -1.675 & 0.176 & $0.000^{* * *}$ & -9.53 \\
\hline
\end{tabular}

The final model consists of twenty explanatory variables, which Eighteen of them found to be significant. Positive and negative signs for estimated coefficients of predictor variables across the model results indicate each predictor variable's increasing or decreasing effect on the injury severity of vehicle-to-vehicle crashes, respectively.

Table 2. Parameter estimates for injury severity analysis of vehicle-to-vehicle crashes using the binary logistic regression model

* Significant at 0.1 level, ** Significant at 0.05 level, *** Significant at 0.01 level 
Significant temporal explanatory variables include early morning and afternoon hours and spring, summer, and autumn seasons. Early morning hours (00:00 to 06:59) are significantly associated with an increase in the severity of vehicle-to-vehicle crashes. The result was expectable because the roads experience very low traffic volumes at this time of the day. This may put drivers at the risk of speedingrelated violations as they can easily reach free-flow speed (FFS) when the streets are uncongested. The resulting speeding violations can increase the severity of crashes. Furthermore, drivers are prone to drowsiness during these hours, specifically unfamiliar drivers who traveled many hours prior to the crash. Afternoon hours (12:00 to 18:59) are the next significant temporal variable that negatively affects the severity of crashes. Contrary to early morning hours, traffic flow approaches the road capacity in the afternoon, and the vehicles' speed decreases significantly. Speed reduction can justify the negative effect on crash severity.

Spring, summer, and autumn seasons are significantly associated with an increase in injury severity of vehicle-tovehicle crashes. This may arise from the better lighting and weather conditions of these seasons compared to winter, which results in an increase in drivers' movement speed. Yet, it is known that pavement condition (in terms of surface friction) is likely to be worse in winters. This concept can make the seasonal-related effects controversial. Accounting for temporal instability $[32,33]$ across the crash data is a possible solution to see if the results are yearly or seasonally stable or not.

Human-related significant variables consist of young atfault drivers as well as at-fault and not-at-fault unfamiliar drivers. Young (less than 31 years old) drivers are found to positively affect the severity of vehicle-to-vehicle crashes when responsible for the crash occurrence (at-fault). This finding is intuitive and is consistent with expectations as young drivers mostly exhibit dangerous behaviors (such as speeding and illegal maneuvers) while driving, more than older drivers. Additionally, young drivers may lack enough experience to do needed maneuvers before collisions (such as distinguishing the best rescue route before a crash) [34]. Unfamiliar drivers are found to be prone to less severe crashes regardless of their percentage of fault. As the literature suggests, it is likely that unfamiliar drivers should be in the road "studying" phase, where the attentional capacity is almost entirely devoted to addressing the unknown situation in the road environment [9]. So, they should be less prone to distraction and less inclined to speeding and risk-taking behaviors since they are not routfamiliar and, of course, confident enough.

On the other hand, familiar drivers are associated with more severe injuries during vehicle-to-vehicle crashes in urban areas. This is because driving on a familiar route is mostly an automatic process in which skill-based tasks are unconscious [35]. Therefore, as previously stated in the literature, a frequent driving condition (route familiarity) can result in distraction and inattention by encouraging mind wandering: the mind is occupied by thoughts not concerning the driving task, and consequentially, responses to external stimuli are potentially slowed down [9]. For the sake of that, inattention can nearly often result in delays in the driver's reaction. Ref. [36] found that route familiar users needed greater reaction times than the unfamiliar drivers in a driving simulator study. Therefore, familiarity can lead drivers to behave in a way that makes them at a higher risk.

Figure 2 reports the ratio of killed/injured to no injury crashes for the studied crash database with regard to drivers' fault and familiarity. As shown in Figure 2, familiar drivers in the database were about two times more prone to severe crashes than unfamiliar counterparts, whether at-fault or not. The descriptive statistics of crash records and modeling results are fairly confirmed by each other.

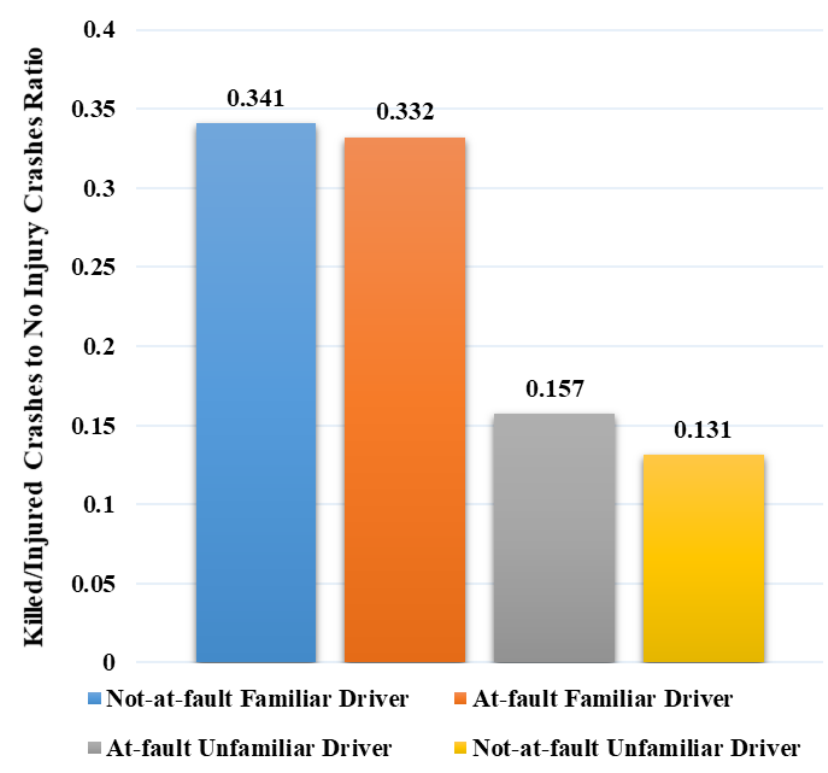

Figure 2. Injury severity level ratio for familiar and unfamiliar drivers by their fault in crashes

Yet, there is a critical issue that unfamiliar drivers may decrease the average speed on roads [37] for the sake of unfamiliarity and less confidence with the route; so, they may choose speeds lower than familiar drivers. In this condition, speed variance increases [9], potentially increasing the crash risk itself. On the other hand, it should be kept in mind that speed-difference-related crashes in urban areas (such as crashes resulting from a sudden change in direction) are not much severe as in rural areas. As a result, unfamiliar drivers may increase the risk or frequency of vehicle-to-vehicle crashes in urban areas, but they decrease the severity of these types of crashes.

Among vehicle-related factors, Iranian-company-made vehicles are determined as a significant predictor variable increasing the severity of vehicle-to-vehicle crashes. The reason for that is the lower safety level of Iranian-companymade vehicles. Many Iranian companies still manufacture vehicles without routine safety-related technologies such as ABS braking systems or airbags. So, regardless of fault and familiarity, Iranian-made cars are more likely to experience severe crashes than foreign-company-made vehicles.

Between all collision angles, head-on and rear-end crashes are found to increase the severity of vehicle-tovehicle crashes. Considering the previous studies, head-on collisions are the most severe vehicle-to-vehicle crashes types [38]. Rear-end collisions are also considered the most frequently occurring types of crashes worldwide and lead to a significant number of injuries and fatalities. In the USA, 
for instance, about one-third of all crashes were rear-end crashes [39]. The involvement of heavy vehicles, darkness, higher speed limits, and impaired drivers can significantly increase the severity of rear-end crashes [39].

The only significant road and environmental-related factor is a crash at night without enough lighting. This is clearly because darkness decreases the drivers' sight distance and increases their reaction time. At last, three crash reasons have become significant in the model. Reverse moving, sudden change in vehicle direction, and sudden opening of the vehicle's door are associated with lower severities of vehicle-to-vehicle crashes. However, these are dangerous behaviors; they cannot inherently cause severe crashes in urban areas. Yet, they can significantly increase the risk of crash occurrence.

As previously stated, to evaluate how accurately the developed model can predict crash severity, a 10-fold crossvalidation process was used. Table 3 reports the results of MAD for 10 separate validation folds.

Table 3. Results for the 10-fold cross-validation

\begin{tabular}{cc}
\hline Validation Fold & MAD \\
\hline 1 & 0.323 \\
2 & 0.317 \\
3 & 0.318 \\
4 & 0.308 \\
5 & 0.307 \\
6 & 0.293 \\
7 & 0.298 \\
8 & 0.285 \\
9 & 0.319 \\
10 & 0.298 \\
\hline
\end{tabular}

The average of MAD values reported in Table 3 is 0.307 . Looking at Table 3, it can be inferred that all the MAD values are fairly close to the average value of MAD (0.307). In addition, considering the target variable values $(0-1)$, the prediction ability of the model seems reasonable but not perfect.

\section{Conclusion}

Drivers' route familiarity and unfamiliarity can be related to increased crash risk, frequency, and severity. Unfamiliar drivers could be involved in errors due to unexpected road features or interaction situations, while familiar drivers seem prone to inattention and risk-taking behavior. This paper aimed to investigate the factors that significantly affect the severity of urban vehicle-to-vehicle crashes in the presence of familiar and unfamiliar drivers. The crash data of Rasht, the biggest city of Guilan province, in Iran were utilized for this target using a binary logistic regression model.

Results highlighted the decreasing effect of unfamiliar atfault and not-at-fault drivers, afternoon hours, the foreigncompany-made vehicles, reverse moving, sudden change in vehicle direction, and sudden opening of the vehicle's door on injury severity of vehicle-to-vehicle crashes. On the other hand, early morning hours, spring, summer, and autumn seasons, head-on and rear-end collisions, Iranian companymade vehicles, dark roads at night, and young at-fault drivers were found to significantly increase the injury severity of vehicle-to-vehicle crashes in urban areas.
The outcomes of this research can assist transportation engineers and researchers in taking more targeted measures to mitigate the severities of vehicle-to-vehicle crashes in urban areas with a large number of tourists and unfamiliar drivers.

\section{References}

[1] WHO, Global status report on road safety 2018 (2018), ed: World Health Organization, 2019.

[2] P. Colonna, Proposal for a safety function for evaluating the road efficiency level, in Traffic And Transportation Studies (2002) 1055-1062.

[3] B. Dimitrijevic, S. D. Khales, R. Asadi, J. Lee, ShortTerm Segment-Level Crash Risk Prediction Using Advanced Data Modeling with Proactive and Reactive Crash Data. Applied Sciences 12 (2022) 856.

[4] S. Singh, Critical reasons for crashes investigated in the national motor vehicle crash causation survey, 2015.

[5] K. L. Young, P. M. Salmon, Examining the relationship between driver distraction and driving errors: A discussion of theory, studies and methods. Safety science 50 (2012) 165-174.

[6] E. Abbasi, Y. Li, A Comprehensive Review of Driver's Attention and the Evaluation Methods. Computational Research Progress in Applied Science \& Engineering (CRPASE) 7 (2021) 2392.

[7] H. Nasr Esfahani, R. Arvin, Z. Song, N. Sze, Prevalence of cell phone use while driving and its impact on driving performance, focusing on near-crash risk: A survey study in Tehran. Journal of Transportation Safety \& Security (2019) 1-21.

[8] P. Intini, P. Colonna, E. O. Ryeng, Route familiarity in road safety: A literature review and an identification proposal. Transportation research part F: traffic psychology and behaviour 62 (2019) 651-671.

[9] P. Intini, N. Berloco, P. Colonna, V. Ranieri, E. Ryeng, Exploring the relationships between drivers' familiarity and two-lane rural road accidents. A multi-level study. Accident Analysis \& Prevention 111 (2018) 280-296.

[10] H. Wen, G. Xue, Injury severity analysis of familiar drivers and unfamiliar drivers in single-vehicle crashes on the mountainous highways. Accident Analysis \& Prevention 144 (2020) 105667.

[11] J. G. Milliken, Council, F.M., Gainer, T.W., Garber, N.J., Gebbie, K.M., Hall, J.W., et al,. Managing Speed: Review of Current Practice for Setting and Enforcing Speed

Limits. Transportation Research Board, 1998.

[12] J. L. Prestopnik, B. Roskos-Ewoldsen, The relations among wayfinding strategy use, sense of direction, sex, familiarity, and wayfinding ability. Journal of Environmental Psychology 20 (2000) 177-191.

[13] H. K. Allen, K. H. Beck, F. Zanjani, Driving concerns among older adults: Associations with driving skill, behaviors, and experiences. Traffic injury prevention 20 (2019) 45-51.

[14] M. Vahedi Saheli, M. Effati, Segment-Based Count Regression Geospatial Modeling of the Effect of Roadside Land Uses on Pedestrian Crash Frequency in Rural Roads. International Journal of Intelligent Transportation Systems Research (2021) 1-19.

[15] M. Effati, M. Vahedi Saheli, Examining the influence of rural land uses and accessibility-related factors to estimate pedestrian safety: The use of GIS and machine learning techniques. International Journal of Transportation Science and Technology (2021) 
[16] M. Vahedi Saheli, M. Effati, Examining the impact of land-use related factors on rural traffic collisions. Journal of Injury and Violence Research 11 (2019).

[17] B. Watson, D. Tunnicliff, J. Manderson, E. O'Connor, The safety of international visitors on Australian roads. (2004).

[18] X. Zhu, S. Srinivasan, Modeling occupant-level injury severity: An application to large-truck crashes. Accident Analysis \& Prevention 43 (2011) 1427-1437.

[19] C. Liu, T. J. Ye, Run-off-road crashes: an on-scene perspective, 2011.

[20] K. Harootunian, B. H. Lee, L. Aultman-Hall, Odds of fault and factors for out-of-state drivers in crashes in four states of the USA. Accident Analysis \& Prevention 72 (2014) 32-43.

[21] K. Harootunian, L. Aultman-Hall, B. H. Lee, Assessing the relative crash fault of out-of-state drivers in Vermont, USA. Journal of Transportation Safety \& Security 6 (2014) 207-219.

[22] T.O. Nævestad, R. O. Phillips, G. Meyer Levlin, I. B. Hovi, Internationalisation in road transport of goods in Norway: safety outcomes, risk factors and policy implications, Safety 3 (2017) 22.

[23] A. Alogaili, F. Mannering, Unobserved heterogeneity and the effects of driver nationality on crash injury severities in Saudi Arabia. Accident Analysis \& Prevention 144 (2020) 105618.

[24] M. Vahedi Saheli, M. Effati, Investigation of factors contributing to pedestrian crash severity in rural roads. Journal of Injury and Violence Research 11 (2019).

[25] M. Effati, H. Behbahani, S. Mortezaei, M. Vahedi Saheli, Modelling and Analyzing the Severity of Two-Lane Highway Crashes Using the Spatial Data mining, Case Study: Old Corridor of Qazvin-Loshan. Journal of Civil and Environmental Engineering (2020).

[26] V. Najafi Moghaddam Gilani, S. M. Hosseinian, M. Ghasedi, M. Nikookar, Data-driven urban traffic accident analysis and prediction using logit and machine learningbased pattern recognition models. Mathematical problems in engineering 2021 (2021).

[27] H. Behbahani, V. N. M. Gilani, M. J. Samet, R. Salehfard, Analysis of crossing speed of the pedestrians in marked and unmarked crosswalks in the signalized and unsignalized intersections (case study: rasht city). In: IOP Conference Series: Materials Science and Engineering, vol. 245, IOP Publishing, 042014 (2017).

[28] I. Bargegol, V. Najafi Moghaddam Gilani, F. Jamshidpour, Relationship between pedestrians' speed, density and flow rate of crossings through urban intersections (case study: rasht metropolis)(RESEARCH NOTE). International Journal of Engineering 30 (2017) $1814-1821$.

[29] S. Pourfalatoun, E. E. Miller, User perceptions of automated Truck-Mounted attenuators: Implications on work zone safety. Traffic injury prevention (2021) 1-8.

[30] S. Washington, M. G. Karlaftis, F. Mannering, P. Anastasopoulos, Statistical and econometric methods for transportation data analysis. CRC press, 2020.

[31] N.-N. Sze, S. Wong, Diagnostic analysis of the logistic model for pedestrian injury severity in traffic crashes. Accident Analysis \& Prevention 39 (2007) 1267-1278.

[32] A. Behnood, F. Mannering, Time-of-day variations and temporal instability of factors affecting injury severities in large-truck crashes. Analytic methods in accident research 23 (2019) 100102.

[33] F. Mannering, Temporal instability and the analysis of highway accident data. Analytic methods in accident research 17 (2018) 1-13.
[34] M. Koloushani, M. Ghorbanzadeh, E. E. Ozguven, M. B. Ulak, Crash Patterns in the COVID-19 Pandemic: The Tale of Four Florida Counties. Future Transportation 1 (2021) 414-442.

[35] J. Rasmussen, Information processing and humanmachine interaction. An approach to cognitive engineering (1986).

[36] M. R. Yanko, T. M. Spalek, Route familiarity breeds inattention: A driving simulator study. Accident Analysis \& Prevention 57 (2013) 80-86.

[37] P. Colonna, P. Intini, N. Berloco, V. Ranieri, The influence of memory on driving behavior: How route familiarity is related to speed choice. An on-road study. Safety science 82 (2016) 456-468.

[38] H. Huang, C. Siddiqui, M. Abdel-Aty, Indexing crash worthiness and crash aggressivity by vehicle type. Accident Analysis \& Prevention 43 (2011) 1364-1370.

[39] S. A. Mohamed, K. Mohamed, H. A. Al-Harthi, Investigating factors affecting the occurrence and severity of rear-end crashes. Transportation research procedia 25 (2017) 2098-2107. 